\title{
Civilisations
}

Revue internationale d'anthropologie et de sciences

humaines

$50 \mid 2002$

Itinéraires belges aux Amériques

\section{IN MEMORIAM ANNIE DORSINFANG-SMETS \\ (1911-2001)}

Peter Eeckhout, Michel Graulich et Jacques Malengreau

\section{OpenEdition \\ Journals}

Édition électronique

URL : http://journals.openedition.org/civilisations/3381

DOI : $10.4000 /$ civilisations.3381

ISSN : 2032-0442

\section{Éditeur}

Institut de sociologie de l'Université Libre de Bruxelles

\section{Édition imprimée}

Date de publication : 1 décembre 2002

Pagination : 7-10

ISBN : 2-87263-180-1

ISSN : 0009-8140

Référence électronique

Peter Eeckhout, Michel Graulich et Jacques Malengreau, «IN MEMORIAM ANNIE DORSINFANG-

SMETS (1911-2001) », Civilisations [En ligne], 50 | 2002, mis en ligne le 01 décembre 2004, consulté le 30 avril 2019. URL : http://journals.openedition.org/civilisations/3381 ; DOI : 10.4000/ civilisations.3381 


\section{IN MEMORIAM \\ ANNIE DORSINFANG-SMETS (1911-2001)}

Annie Dorsinfang-Smets, doyenne des Américanistes belges, est décédée à Uccle le 10 janvier 2001 à l'âge de 90 ans. Docteur en Philosophie et Lettres (philologie classique) et licenciée en Histoire de l'Art et Archéologie de l'Université Libre de Bruxelles, elle débute sa carrière en 1937 comme assistante en archéologie classique à l'ULB et maître de conférences à l'Ecole Supérieure des Arts Décoratifs. L'année suivante, elle enseigne parallèlement l'histoire des civilisations à l'Ecole Supérieure de Secrétariat. En 1939, elle part pour le Congo où elle restera bloquée par la guerre jusqu'en 1946. Elle reprend ses activités académiques en 1949 à l'Ecole Supérieure de Secrétariat, la même année où est publié son premier article à caractère scientifique, consacré à des vases équatoriens des collections du Musée du Cinquantenaire (voir bibliographie ciaprès). Collaboratrice de la Section d'Ethnographie du Musée, elle publiera durant une dizaine d'années, en Belgique et à l'étranger, une série d'articles relatifs aux pièces d'archéologie américaine qui y sont conservées. En 1953, elle est nommée Directrice de l'Ecole Sociale Coloniale où elle donnera durant sept ans le cours d'Initiation à la vie indigène. Elle abandonnera cette fonction en 1960 pour celle de professeur ordinaire à l'Université Libre de Bruxelles, charge qu'elle assumera jusqu'à sa retraite en 1980. Anthropologie Sociale, Contacts de Cultures et Arts non européens constitueront les axes majeurs de ses cours. De 1962 à 1971, elle donnera également le cours "Arts Primitifs " à l'Institut Supérieur d'Art et d'Archéologie à Bruxelles. De nombreux américanistes belges ont suivi ses enseignements ou ont bénéficié de son encadrement 
Annie Dorsinfang-Smets a également exercé de nombreuses charges dans diverses sociétés savantes: présidente de la Société Royale Belge d'Anthropologie et de Préhistoire (1960-61), Présidente de la Société Belge de Sociologie (1963-64), Membre associé de l'Académie Royale des Sciences d'Outre-Mer et, depuis 1975, Directrice de la commission belge chargée de la préparation du Corpus des Antiquités américaines en Belgique (patronné par l'Union Académique Internationale).

Mais par-delà ses fonctions officielles, Annie Dorsinfang-Smets n'a jamais ménagé ses encouragements et ses conseils à ses collègues plus jeunes, tout en motivant ses collaborateurs et son entourage académique par sa disponibilité, sa gentillesse et la considération qu'elle portait toujours à leurs travaux et à leurs préoccupations.

Dynamique et enthousiaste jusque dans les dernières années, elle avait activement participé à la renaissance de la Société des Américanistes de Belgique, dont elle était Présidente d'honneur depuis 1993. Le présent volume est dédié à sa mémoire.

Peter Eeckhout

Michel Graulich

Jacques Malengreau

\section{Bibliographie relative à l'Amérique :}

1949a, Céramique de la province d'Esmeraldas (Equateur). Bulletin des Musées Royaux d'Art et d'Histoire 21 (1-6):87-90.

1949b, Acquisitions récentes du Département d'archéologie américaine. Bulletin des Musées Royaux d'Art et d'Histoire 21 (1-6):91-97.

1951a, Sacs à coca du Chili. Bulletin des Musées Royaux d'Art et d'Histoire $23: 101-$ 105.

1951b, Les « sièges » du Costa Rica aux Musées Royaux d'Art et d'Histoire. Bulletin de la Société Royale Belge d'Anthrop. et de Préhistoire 62 :72-79.

1953a, Un oiseau d'or de Colombie. Bulletin des Musées Royaux d'Art et d'Histoire $25: 82-89$.

1953b, Le lapin dans la mythologie aztèque et ailleurs. Bulletin de la Société Royale Belge d'Anthropologie et de Préhistoire 64 :119-139.

1954, Contacts de cultures et problèmes d'acculturation en Amérique du Sud. Revue de l'Institut de Socialogie 3 : 29-50

1955a, Contactos entre Culturas y problemas de aculturación en América del Sur. América Indígena 20: 271-291. 
1955b, Les metates du Costa Rica des Musées Royaux d'Art et d'Histoire (Bruxelles). Journal de la Société des Américanistes 44 :131-147.

1955c, Notes de voyage au Mexique et au Guatemala. Bulletin des Musées Royaux d'Art et d'Histoire $27: 104-110$.

1954, Les coupeurs de têtes de Costa-Rica. Bulletin de la Société Royale Belge d'Anthropologie et de Préhistoire 67 :89-111.

1958a, Un fumeur de cigares de l'Amérique précolombienne. Bulletin des Musées Royaux d'Art et d'Histoire 30 :105-110.

1958b, Une dalle sculptée d'Amérique Centrale. Journal de la Société des Américanistes 47 :55-66.

1962, La recherche du salut chez les Indiens d'Amérique. Religions de Salut, Annales du Centre d'Etudes des Religions 2: 113-125. Institut de Sociologie, Bruxelles.

1963a, Le Mexique parmi nous : à propos de la collection Paulus de précolombiens. Terre d'Europe $21: 43-51$.

1963b, Pérennité de l'Afrique à Cuba. L'Arc 38 : 89-93.

1964a, Les cultes solaires aux Amériques à l'époque de la conquête espagnole. Actes $d u$ Colloque "Le Soleil à la Renaissance ", pp. 365-80. Institut pour l'Etude de la Renaissance, Bruxelles.

1964b, L'Amérique Précolombienne. Collection Religions du Monde. Bloud \& Gay, Paris.

1964c, Fins du Monde Successives. Essais d'interprétation culturelle. Actas y Memorias del 35to Congreso Internacional de Americanistas, Mexico 1962 (Vol.2), ed. Lauro José Zavala, y Noemí Castillo Tejero, pp.3-9. Mexico.

1968, Aspects particuliers du métissage culturel en Amérique latine. Cahiers internationaux de Sociologie 44 :79-93.

1969a, L'Art dans les sociétés autochtones des Amériques. La nouvelle Bibliothèque de l'Honnête Homme, Bruxelles.

1969b, Gouvernants ef gouvernés dans l'Amérique indienne. Gouvernants et Gouvernés, Recueils de la Société Jean Bodin pour l'Histoire Comparative des Institutions 23 :317-38. 
1969c, Les quatre coins du monde aztèque. Eschatologie et Cosmologie, Annales du Centre d'Etudes des Religions $3: 59-71$. Institut de Sociologie, Bruxelles.

1969d, Fins du monde en Amérique précolombienne. Eschatologie et Cosmologie, Annales du Centre d'Etudes des Religions 3 :73-88. Institut de Sociologie, Bruxelles.

$1969^{\mathrm{e}}$, Sacrifices et pénitences chez les Amérindiens. A propos de quelques remarques de Bernardino de Sahagún sur les usages rituels aztèques. Eschatologie et Cosmologie, Annales du Centre d'Etudes des Religions 3:90-100. Institut de Sociologie, Bruxelles.

1973a, Les « empires " d'Amérique précolombienne. Les grands empires, Recueils de la Société Jean Bodin pour l'Histoire Comparative des Institutions 31 :725-31.

1973b, L'Amérique précolombienne : les civilisations du maïs. (avec la collaboration de P. Hubot et A-M. d'Ans). Meddens, Bruxelles.

1974a, Introduction au Catalogue de l'exposition "les Masques du Monde ", Société Générale de Belgique, Bruxelles.

1975a, Introduction. L'Amérique du Nord. Histoire et Culture, pp. 1-12. Meddens, Bruxelles.

1975b, Les Indiens. L'Amérique du Nord. Histoire et Culture, pp. 25-51. Meddens, Bruxelles.

1976, Art de la Mésoamérique. Introduction au catalogue de l'exposition de la Société Générale de Banque (17/11/1976 - 8/1/1977). Bruxelles.

1977, Masques et masqués en Amérique indienne. Académie Royale des Sciences d'Outre-Mer, Bulletin des Séances de l'année 1977, 2 :130-138.

1978, Les aspects multiples de Quetzalcoatl. Mélanges Armand Abel, éd. A. Destrée, pp46-58. Brill, Leiden

1985, Henry Lavachery, 1885-1972. Académie Royale de Belgique, Bulletin de la Classe des Beaux-Arts 67 :277-82.

en collaboration avec Michel Graulich :

1980, Nouvelles découvertes d'archéologie mexicaine : les peintures murales de Cacaxtla et les fouilles du Grand Temple de Mexico. Annales d' Histoire de l'Art et d'Archéologie de l'Université Libre de Bruxelles 2 :53-57. 